\title{
BMJ Open Perceptions and experiences of healthcare workers during the COVID-19 pandemic in the UK
}

\author{
Cecilia Vindrola-Padros (D) , ${ }^{1}$ Lily Andrews, ${ }^{2}$ Anna Dowrick, ${ }^{3}$ Nehla Djellouli, ${ }^{4}$ \\ Harrison Fillmore, ${ }^{5}$ Elysse Bautista Gonzalez, ${ }^{2}$ Dena Javadi, ${ }^{6}$ \\ Sasha Lewis-Jackson, ${ }^{5}$ Louisa Manby, ${ }^{2}$ Lucy Mitchinson, ${ }^{7}$ \\ Sophie Mulcahy Symmons, ${ }^{2}$ Sam Martin, ${ }^{8}$ Nina Regenold, ${ }^{5}$ Hannah Robinson, ${ }^{9}$ \\ Kirsi Sumray, ${ }^{2}$ Georgina Singleton, ${ }^{1}$ Aron Syversen, ${ }^{2}$ Samantha Vanderslott, ${ }^{8}$ \\ Ginger Johnson ${ }^{1}$
}

To cite: Vindrola-Padros C, Andrews L, Dowrick A, et al. Perceptions and experiences of healthcare workers during the COVID-19 pandemic in the UK. BMJ Open 2020;10:e040503. doi:10.1136/ bmjopen-2020-040503

- Prepublication history and additional material for this paper are available online. To view these files, please visit the journal online (http://dx.doi. org/10.1136/bmjopen-2020040503).

Received 15 May 2020 Revised 07 October 2020 Accepted 18 0ctober 2020

Check for updates

(c) Author(s) (or their employer(s)) 2020. Re-use permitted under CC BY-NC. No commercial re-use. See rights and permissions. Published by BMJ.

For numbered affiliations see end of article.

Correspondence to Cecilia Vindrola-Padros; c.vindrola@ucl.ac.uk

\section{ABSTRACT}

Objective The COVID-19 pandemic has set unprecedented demand on the healthcare workforce around the world. The UK has been one of the most affected countries in Europe. The aim of this study was to explore the perceptions and experiences of healthcare workers (HCWs) in relation to COVID-19 and care delivery models implemented to deal with the pandemic in the UK. Methods The study was designed as a rapid appraisal combining: (1) a review of UK healthcare policies $(n=35$ policies), (2) mass media and social media analysis of front-line staff experiences and perceptions $(n=101$ newspaper articles, $n=146000$ posts) and (3) indepth (telephone) interviews with front-line staff $(n=30$ interviews). The findings from all streams were analysed using framework analysis.

Results Limited personal protective equipment (PPE) and lack of routine testing created anxiety and distress and had a tangible impact on the workforce. When PPE was available, incorrect size and overheating complicated routine work. Lack of training for redeployed staff and the failure to consider the skills of redeployed staff for new areas were identified as problems. Positive aspects of daily work reported by HCWs included solidarity between colleagues, the establishment of well-being support structures and feeling valued by society.

Conclusion Our study highlighted the importance of taking into consideration the experiences and concerns of front-line staff during a pandemic. Staff working in the UK during the COVID-19 pandemic advocated clear and consistent guidelines, streamlined testing of HCWs, administration of PPE and acknowledgement of the effects of PPE on routine practice.

\section{BACKGROUND}

Research on the design and implementation of global epidemic response efforts has pointed to the importance of considering staff perceptions and experiences of care delivery. Research from high-income settings highlights the following factors as influencing the behaviour of healthcare workers (HCWs)
Strengths and limitations of this study

- The study captured the experiences of healthcare workers (HCWs) during the prepeak, peak and early postpeak of the COVID-19 pandemic in the UK.

- The study combined data from three sources: public policies, media (newspaper articles and social media) and interviews with front-line staff.

- Most of the interview participants were doctors and had high levels of seniority leading to the limited representation of the views of HCWs.

- We made an effort to identify themes that cut across media, policy and interview data through a process of triangulation, but it is important to consider that these data were generated in different contexts and for different purposes.

- Even though the media analysis and policy review were national in scope, the interviews were mainly carried out in London (potentially missing other experiences across the country).

during epidemics: fear of contagion, concern for family health, interpersonal isolation, quarantine, trust in and support from their organisation, information about risks and what is expected of them, and stigma. ${ }^{1-3}$ Experience from the 2003 SARS outbreak provides evidence that HCWs experience anxiety, stress and fear due to providing direct patient care. ${ }^{4}$ During an outbreak, HCWs work long hours under pressure, often without adequate resources and while accepting inherent dangers. These conditions can also cause discomfort with government policies and guidelines (eg, guidelines of reuse of personal protective equipment (PPE) $).{ }^{45}$

In order to offset the fears and uncertainties mentioned above, staff benefit from strong leadership, supportive supervision, peer support networks and access to reliable 
communication technology. ${ }^{4}$ Potential strategies to mitigate stress include: organisational implementation of infection prevention control, delivery of staff training and complying with the supply of PPE. ${ }^{17-9}$ These studies have called for more research into factors that influence HCWs' experiences of providing care during infectious disease outbreaks.

The COVID-19 pandemic has set unprecedented demand on healthcare systems globally. Emerging research from multiple countries have included reports of HCW fatigue, distress and anxiety as well as positive emotional responses (eg, 'growth under pressure') and helpful coping mechanisms. ${ }^{10-12}$ In the case of the UK, the COVID-19 pandemic impacted a public healthcare system, the National Health Service (NHS), already struggling with workforce issues including high vacancy and low retention rates of staff, limited bed capacity, and funding cuts. ${ }^{13}$ On 23 March 2020, the UK went into lockdown with social distancing policies implemented across the population in an attempt to reduce the transmission of COVID-19 and the burden on the healthcare system. In order to increase capacity across hospitals, the NHS announced on 15 April 2020 the prioritisation of cancer treatments and suspension of all non-urgent elective surgery for 3 months. Operating theatres were also repurposed, and private facilities were commissioned for NHS services. ${ }^{14}$

Strategies to address workforce gaps included: the redeployment of staff, the reintegration of recently retired staff into the active workforce, and early graduation of medical students. ${ }^{12}$ Recent surveys have reported staff anxiety and fears regarding their ability to safely carry out their daily work. ${ }^{15} 16$ However, more in-depth, qualitative analyses of the experiences of front-line staff in the UK during the COVID-19 pandemic are missing. We have sought to address this gap by carrying out a rapid appraisal to explore the perceptions and experiences of HCWs in relation to COVID-19 and care delivery models implemented to deal with the pandemic in the UK.

\section{RESEARCH QUESTIONS}

The main research questions guiding the study were:

1. What are HCWs experiences of delivering care in the context of the COVID-19 pandemic?

2. Do HCWs feel they have the proper training and supplies to work with patients potentially infected with COVID-19? If not, what additional resources would help them to do their work more effectively?

3. Do HCWs experience any concerns delivering care in the context of a pandemic? If so, what are the underlying causes of their concerns with regards to COVID-19 and how can these be addressed?

\section{METHODS}

The study was designed as a rapid appraisal combining three streams of work: (1) a review of UK healthcare policies, (2) mass media and social media analysis of front-line staff experiences and perceptions during the pandemic and (3) in-depth (telephone) interviews with front-line staff (see table 1). In this article, we share

Table 1 Rapid appraisal design

\begin{tabular}{|c|c|c|c|}
\hline Data source & Method of data collection & Sample & Method of data analysis \\
\hline Media analysis & $\begin{array}{l}\text { Review of newspaper articles } \\
\text { obtained from LexisNexis. }\end{array}$ & $\begin{array}{l}101 \text { newspaper articles published } \\
\text { between } 1 \text { December } 2019 \text { and } 20 \\
\text { April } 2020 .\end{array}$ & $\begin{array}{l}\text { Data extracted using REDCap and analysed } \\
\text { for content using framework analysis (coding } \\
\text { carried out by two researchers). }\end{array}$ \\
\hline $\begin{array}{l}\text { Front-line staff } \\
\text { interviews }\end{array}$ & $\begin{array}{l}\text { In-depth, semistructured telephone } \\
\text { interviews with a purposive sample } \\
\text { of staff. }\end{array}$ & $\begin{array}{l}30 \text { staff members working in } \\
\text { emergency departments and intensive } \\
\text { care units in three hospitals: }\end{array}$ & $\begin{array}{l}\text { RAP sheets were used to synthesise findings } \\
\text { on an ongoing basis. Selected transcripts } \\
\text { were generated and analysed using } \\
\text { framework analysis. }\end{array}$ \\
\hline
\end{tabular}

Male: 13

Female: 17

Nurses: 3

Doctors: 25

Allied health professionals: 2

Senior staff: 18

Junior staff: 12

NHSE, National Health Service England; PHE, Public Health England; RAP, rapid assessment procedures; REDCap, Research Electronic Data Capture. 
emerging findings from this study based on data collected from December 2019 to the end of April 2020 (covering the pandemic prepeak, peak and early postpeak). Rapid appraisals are commonly developed to collect and analyse data in a targeted and iterative way within limited timeframes, often to 'diagnose' a situation. ${ }^{17}{ }^{18} \mathrm{~A}$ rapid appraisal design often combines two or more methods of data collection and then uses triangulation from different sources as a form of data validation. ${ }^{19}$ The research team included junior and senior researchers with backgrounds in medical anthropology, public health and medicine. The team leads had experience carrying out rapid qualitative research in the context of infectious epidemics.

\section{UK healthcare policy review}

The aim of the healthcare policy review was to understand how healthcare delivery has been reorganised in light of the COVID-19 pandemic in the UK. We followed the framework set out by Tricco $e t a l^{19}$ for rapid evidence synthesis. We searched for government policies on legislation.gov.uk, gov.uk, NHS England and Public Health England (PHE) databases using the search strategy and inclusion criteria included in online supplemental appendix 1.

One researcher selected the policies that met these criteria. A second researcher reviewed the policies and extracted data regarding the type of policy, healthcare sector it was aimed at, the type of changes in healthcare delivery it proposed and the duration of these changes. Data were cross-checked across reviewers. Using framework analysis, ${ }^{20}$ a third researcher with expertise in health systems analysis identified the main topics emerging from the data and developed a conceptual framework tailored to the unique characteristics of the COVID-19 response. The framework development was cross-referenced with elements described in the WHO's Strategic Framework for Emergency Preparedness and Khan et $a l \mathrm{~s}^{21}$ Public Health Emergency Preparedness Framework. The tailored framework became a working document that was modified as new policies were added to the analysis, and as existing policies were amended by government authorities.

\section{Mass media and social media analysis}

The aim of the media analysis was to capture the perceptions and experiences of HCWs as reported by them or third parties in the media. We used the same approach for rapid evidence synthesis as in the case of the policy review. The media analysis included a review of mass media (mainly newspaper articles) and social media.

\section{Mass media}

We reviewed published newspaper articles by running a search on the Nexis database. The full-search strategy and inclusion criteria can be found in online supplemental appendix 1. Results were exported into Excel spreadsheets. We also handsearched newspaper and magazine articles in relevant media sources. One researcher screened the articles in the title and full-text phase, and two researchers cross-checked exclusions. Disagreements were discussed until consensus was reached.

The included articles were analysed using a data extraction form developed in Research Electronic Data Capture (REDCap). The form was developed and piloted after the initial screening of full-text articles by two independent researchers using a random sample of five articles. Disagreements were discussed until consensus was reached. The data extraction form was finalised based on the findings from the pilot. Data were exported from REDCap and the main article characteristics were synthesised. The information entered was exported from REDCap and analysed using framework analysis. ${ }^{20}$

\section{Social media}

Our sample concentrated on Twitter, but we also searched for relevant content on Reddit, Facebook (publicly available groups), Instagram (public accounts) and YouTube. Using the media monitoring software 'Meltwater', ${ }^{22}$ we conducted an English language Boolean query keyword search. The search terms were adapted from those used for the mass media search, excluding for irrelevant posts. All posts were coded by two researchers into predefined categories to create a final dataset. We checked intercoder reliability and code in parallel to determine if this diverged too greatly below a predetermined accuracy score.

Once the initial coding was complete, we cleaned the dataset of duplicates or semiduplicates (eg, when a post is retweeted with the prefix 'RT' or by a user/bot that uses random characters to avoid being recognised by Twitter detection algorithms for mass postings). We used semantic discourse and topic analysis in order to understand the most frequent and weighted keywords, viral hashtags and prioritised themes of discussion, and clusters of topics (within and across countries) with a primary focus on the UK. The analysis was put into context with the outbreak situation in the UK, and the corresponding response of the government and public to the operation of the health system.

\section{In-depth (telephone) interviews}

In-depth, semistructured interviews with front-line staff were carried out over the telephone during April 2020, and audio recorded with consent of the participants. Interviews with staff are ongoing and will continue to document perceptions and experiences as the pandemic evolves. Interview topics focused on HCW perceptions of the virus, patients, and the healthcare system (see interview topic guide in online supplemental appendix 2). Following a rapid appraisal design, five interviewers took detailed notes during the interviews (in addition to the audio recording).

\section{Recruitment and ethical review}

Local hospital leads identified potential research participants based on a pre-established sampling framework. 
Potential participants were provided with a copy of the participant information sheet and were asked if they would be interested in being contacted by a researcher. If they agreed, the researcher then sent them the participant information sheet again and asked them if they had any questions about the study. If the staff member agreed to take part in the study, they were asked to sign a consent form and the researcher arranged a time for the telephone interview. Participants were reminded that their participation in the study was voluntary, they could withdraw at any time and the research team would maintain their anonymity. No participants decided to withdraw throughout the course of the study.

\section{Sampling}

The interviews were carried out with a purposive sample of HCWs delivering care in three hospitals (see table 1 for a description of the professional groups). The sampling was guided by a sampling framework designed to recruit participants from different professional groups, gender and levels of seniority.

\section{Analysis of interview data}

The interview notes were imported into a summarising rapid assessment procedures (RAP) sheet. ${ }^{23}$ RAP sheets allowed for the early identification of findings and facilitated the implementation of analysis as data collection was ongoing. Key segments of interview data were also selectively transcribed and analysed using framework analysis. Members of the research team familiarised themselves with the data and developed an initial coding framework. After the framework was agreed, it was applied to the interview transcripts and data were charted in an Excel spreadsheet. The categories used for the framework were informed by our research questions but we were also sensitive to topics emerging from the data. After the data were charted, we explored the framework categories for relationships.

\section{RESULTS}

In this section, we present the main emerging findings from the three streams of work (see table 2 for a summary).

\section{Changing guidelines and limited training}

Some HCWs were redeployed and relieved of their regular duties to provide support for a surge in admissions and increase capacity in intensive care unit (ICU). Staff reported feelings of apprehension regarding redeployment, but described colleagues as very supportive through the transition. Very few HCWs reported being adequately trained for their redeployment; often, PPE training or PPE simulation was the only support available from management. The analysis of newspaper articles indicated that HCWs felt that advice, information and training were insufficient (or too rapidly changing), this feeling was demonstrated further in the social media analysis. HCWs communicated the inconsistency in advice and in many cases, this led to an increased sense of lack of preparedness and ability to cope.

Social media analysis found that to support each other through the need for training and changes in delivery of care and redeployment, HCWs were setting up weekly chats via Twitter around specific hashtags (eg, \#PhysioTalk), where discussions of new COVID-19 procedures in the treatment and rehabilitation of patients and online training slides were shared. Remote training materials were also utilised for newly redeployed staff, while evolving guidelines were adapted to help train medical students close to graduating. Transcripts of these chats and any policy or other documents shared were archived on related websites/online platforms, so that HCWs could refer to these on an ongoing basis.

\section{Testing of HCWs}

Our policy review indicated that, by 27 March 2020, the government set to establish a testing programme using three laboratories to develop testing kits for all NHS staff with the objective of testing all HCWs for COVID-19. ${ }^{24}$ Our interviews indicated that staff perceived the testing of HCWs as an intrinsic component of sustaining a healthy workforce throughout the pandemic, though there was ambivalence about the speed and effectiveness of tests. This ambivalence was especially true during the first few weeks of the pandemic, when staff reported having to stay home if they or someone in their household presented with symptoms indicative of COVID-19, putting extra pressure on the remaining staff. This reportedly improved towards the end of data collection, but tests were still difficult to access for some and high levels of false negatives remained an issue.

\section{Concerns about contagion and personal wellbeing}

One of the main areas of concern, particularly towards the end of data collection was related to PPE. The policy review indicated that, prior to addressing a patient's needs, HCWs must don the appropriate PPE and ensure adequate hand hygiene. Despite the fact that some of the PPE recommended for use during the COVID-19 outbreak is single use, on 17 April 2020, PHE approved the reuse of PPE in cases where there was an acute shortage and where it was 'safe to do so'. ${ }^{25}$

The analysis of newspaper articles indicated that there was frustration expressed by HCWs at changing advice, hospitals not keeping up-to-date or lack of advice all together. Advice, information and training enveloped PPE, self-isolation, quarantining of patients, testing and the protection of HCW's (and their families). In the interviews, many HCWs stated that PPE guidance had changed multiple times for specific procedures and across the hospital (sometimes every week); donning PPE incorrectly and then bringing the virus home to their families had therefore become a source of anxiety. One senior doctor reported, 'PPE training only happened because of local engagement from clinicians rather than 
Table 2 Summary of findings from all three workstreams

\begin{tabular}{llll}
\hline $\begin{array}{l}\text { Emerging findings from all } \\
\text { three workstreams }\end{array}$ & $\begin{array}{l}\text { Examples from media } \\
\text { analysis (including social } \\
\text { media) }\end{array}$ & $\begin{array}{l}\text { Representative quotes from the } \\
\text { interviews }\end{array}$ & Content from UK policies \\
\hline $\begin{array}{l}\text { Concerns about changing and } \\
\text { inconsistent guidelines }\end{array}$ & $\begin{array}{l}\text { Staff used social media to } \\
\text { share guidelines among } \\
\text { colleagues. }\end{array}$ & $\begin{array}{l}\text { 'A protocol a day for every single } \\
\text { step(...)becomes obsolete after }\end{array}$ & $\begin{array}{l}\text { Policies related to PPE, for } \\
\text { instance, changed over the } \\
\text { course of the pandemic, with } \\
\text { one major change being the } \\
\text { allowance of PPE reuse. }\end{array}$ \\
\end{tabular}

Lack of training (for redeployed Newspaper articles indicated staff but also in relation to PPE) that HCWs felt that advice, information and training were insufficient.
We had training on a specific kind of face mask but other than that have not really had training.' 'In ICU the non-specialist nurses change every day and have to relearn skills.'

\begin{tabular}{ll}
$\begin{array}{l}\text { Lack of streamlined and } \\
\text { inconsistent testing of NHS staff }\end{array}$ & $\begin{array}{l}\text { 'Many healthcare professionals } \\
\text { are questioning why they, } \\
\text { as front-line NHS staff, are } \\
\text { continuing to be denied testing } \\
\text { for COVID-19 while an MP } \\
\text { (Member of Parliament) has } \\
\text { not' (News article, 12 March } \\
2020)\end{array}$ \\
\hline $\begin{array}{l}\text { Difficulties with PPE use (size, } \\
\text { overheating, dehydration) }\end{array}$ & $\begin{array}{l}\text { HCWs tweeted about } \\
\text { dehydration and the challenges } \\
\text { of PPE use when fasting during } \\
\text { Ramadan. }\end{array}$
\end{tabular}

Good well-being support

Solidarity among colleagues

Demonstration that quick changes are possible in the healthcare system
On social media some HCWs affirmed pride in doing their jobs on the front-line despite challenges and fatigue.
'Staff are jeopardising the life of their own families.'

'At one point we were told we might not get tested even though one person in the team had confirmed COVID-19 which seemed to go against previous suggestions.'

'Claustrophobic, even for half an hour. You can't breathe, it is hot and heavy. Can't interact properly.' 'Even the small-sized masks are designed for small men rather than women.'

\section{'We've got a whole well-being} group that we've set up...there's been a lot of focus on trying to help staff through this.'

'We are busting a gut to do what we can for staff morale.'

'The way people come together in a crisis has been a very enjoyable part of it...staff have formed new connections which I think they'll strengthen our network at work and strengthen the way we work together.'

'We would not expect our
system to be overwhelmed but
would expect it to be radically
changed (News article,
05/03/2020).'

'Demonstrated that change can be Rapid establishment of done quickly, what normally takes 3 laboratories to develop a year can be done in week (red COVID-19 testing kits to test tape). We are able to do more in a HCWs. short time.'

'Some of what we've had to do will be the catalyst for changes that we thought we would make at some point in the future but hadn't had the means to do.'
Policies and the infrastructure for testing HCWs increased throughout the study.

Guidelines urged HCWs following Ramadan, and their their need to take breaks and stay hydrated while fasting and wearing PPE.

National guidelines have included more information on revised methods of delivering mental health services than on their availability and use by health workers. NHS colleagues, to support management.' Anxiety was worsened by media reports of HCWs becoming ill. Where staff were confident with PPE supply, this was because managers fought to ensure their staff had enough. Visors were mentioned as being specifically hard to locate.

PPE sizes were considered too large by some of the female staff and there were reports of staff overheating during long shifts wearing PPE combined with difficulties taking water and toilet breaks while wearing equipment. The interviews carried out towards the end of April found that the warmer climate (and lack of airconditioned hospital facilities) and the start of Ramadan exacerbated these difficulties. Some staff reported that regulations implemented to allow HCW breaks every 
2 hours wearing PPE were often not feasible due to limited staff capacity, guilt at 'wasting' PPE (in single use equipment) and the time burden of changing in and out of PPE. On social media, worry surrounding dehydration was also expressed by HCWs tweeting about dehydration and fasting during Ramadan $(\mathrm{n}=30$ tweets between 15 April and 26 April). This was met with response from various NHS hospital and hospital Twitter accounts and a collaboration between the NHS Muslim network, the British Islamic Medical Association and the NHS $(n=10$ tweets). They shared links and infographic guidelines on Twitter, urging HCWs following Ramadan and their NHS colleagues to support the need to take breaks and stay hydrated while fasting and wearing PPE. ${ }^{26}$

\section{Areas of good practice}

Many staff members reported that working conditions were very stressful and anxiety-inducing, but that wellbeing support was variable across hospitals. Many HCWs appreciated the increased availability of psychological support and having a physical space they could use for breaks (eg, 'wobble rooms', sofas, health hubs). However, some staff called for more support on site and the establishment of support programmes that could align to their current working dynamics: 'Part of the problem for the official support, there is a psychologist who's offering sessions, but they are in the middle of the day. So, you wouldn't be able to go if you were on nights, or if you are clinically busy you can't really attend that in the middle of the shift' (Anaesthetist). HCWs expressed many positive feelings regarding the morale and camaraderie of staff. Many voiced their appreciation of food support from neighbours and local businesses and felt that the public really recognised the importance of the NHS. On social media, a wide variety of HCWs affirmed pride in their jobs and called on the need to be adaptable, resilient and flexible, often using the \#NHSheroes hashtag. HCWs were appreciative of the positive messages and rainbow pictures from the public and donations, especially visors. Several HCWs called for a better celebration of successes by sharing good news stories and figures about patients recovering and being discharged.

\section{Recommendations for other countries and future pandemics}

When asked about recommendations, staff continuously requested improved testing and consistent guidance for PPE for all staff. Staff also explained that allowing breaks every 2 hours while wearing PPE was effective in preventing dehydration. It was mentioned that there needed to be improved redeployment of staff, specifically nurses. There were concerns that some nurses were sent to new areas without considering their skillset. Clearer guidance at an earlier stage was also called for, specifically in relation to training. Some senior doctors felt that they had to take control and offer training, rather than it being delivered by managers.

Overall, it was widely reported that the pandemic had instigated rapid changes to the system, of which many would usually take a long time to implement. Several HCWs believed that change in the system should be continued and that improvements should not be undone. For example, one senior doctor explained that with moving forward, 'the key thing is to not reduce the care capacity once it's been increased.'

\section{DISCUSSION}

The COVID-19 pandemic in the UK shed light on existing fractures and deficiencies in the healthcare system related to underfunding, workforce deficiencies, and fragmentation. Our study found similar concerns from front-line staff relating to care delivery during COVID-19 as those reported by other countries. ${ }^{27-29}$ Rapidly changing guidelines, limited PPE and lack of routine testing created anxiety and distress and had a tangible impact on efforts to maintain a sustainable workforce. When PPE was available, incorrect sizes and overheating complicated routine work. A recent review on factors acting as barriers and enablers in HCWs' adherence to infection control guidelines confirmed these findings. ${ }^{30}$

The redeployment of HCWs was used as a strategy to deal with capacity concerns, but lack of training for redeployed staff and the failure to consider the skills of redeployed staff and their match to the skills needed in new areas were identified as problems. Recent publications on staff redeployment to ICUs during the pandemic have highlighted the importance of carrying out detailed skills assessments of redeployed staff to ensure their expertise are used proactively to address patient needs. ${ }^{31} 32$ Some publications have also underscored the importance of intensive, yet comprehensive, training programmes for redeployed staff, particularly those that combine classroom and practice-based training and seek to build skillsets in the workforce that will be maintained after the epidemiological peak. ${ }^{33} 34$ This last point on the sustainability of a skilled workforce has become particularly relevant as several countries are having to rely on redeployment on a nearly continuous basis to deal with the demand of second and third surges of patients.

In the case of our study, positive aspects of daily work reported by HCWs included solidarity between colleagues (in person and through social media platforms), the establishment of well-being support structures, and feeling valued by society. Sun and colleagues ${ }^{10}$ report a similar situation in China, where good teamwork within nursing teams generated positive emotions during the pandemic. Several authors have also highlighted the importance of clear guidelines for well-being support, ${ }^{11}{ }^{12}$ but we would argue that these guidelines need to be developed without losing sight of the realities of HCWs working on the ground, where fatigue and work pressures might not allow them to visit group support meetings or make use of quiet rooms for relaxation. ${ }^{35}$

A positive factor outlined by HCWs in the UK was that they felt that they were able to implement changes in routine practice at a rapid pace. The pressures generated 
by the pandemic restructured internal processes, so clinicians and managers working on the front-line felt their proposals were heard by senior staff, removing the usual 'red tape'. A question that remains is the extent to which these approaches to transformation and quality improvement will remain after the pandemic has subsided or as Swaithes and colleagues have asked, how can we 'lock' in this learning?. ${ }^{36}$ According to these authors, the maintenance of collaborative relationships, strategic leadership and a focus on organisational learning will be key components in the permanence of continuous service improvement.

Our study highlights the importance of taking into consideration the experiences and concerns of front-line staff during a pandemic. In the case of COVID-19, staff have advocated in favour of clear and consistent guidelines, streamlined testing of HCWs, administration of PPE and acknowledgement of the effects of PPE on movement and heat. Our study has also shown that supportive working environments can be motivating for staff under pressure and valuable learning-particularly in relation to the processes used to make improvements in care delivery-can emerge from the challenging circumstances of delivering care in the context of a pandemic.

\section{Author affiliations}

${ }^{1}$ Department of Targeted Intervention, University College London, London, UK ${ }^{2}$ Institute of Epidemiology and Healthcare, University College London, London, UK ${ }^{3}$ Institute of Population Health Sciences, Queen Mary University of London, London, UK

${ }^{4}$ Institute of Global Health, University College London, London, UK

${ }^{5}$ Department of Anthropology, University College London, London, UK

${ }^{6}$ Harvard TH Chan School of Public Health, Department of Social and Behavioral Sciences, Harvard University, Cambridge, Massachusetts, USA

${ }^{7}$ Marie Curie Palliative Care Research Department, Division of Psychiatry, University College London, London, United Kingdom

${ }^{8}$ Oxford Vaccine Group, Centre for Clinical Vaccinology and Tropical Medicine (CCVTM), Oxford University, Oxford, UK

${ }^{9}$ School for Policy Studies, Bristol University, Bristol, United Kingdom

Twitter Cecilia Vindrola-Padros @CeciliaVindrola, Elysse Bautista Gonzalez @ ElysseBg, Louisa Manby @LJ_Manby, Sam Martin @DigitalCoeliac, Nina Regenold @NinaRegenold and Samantha Vanderslott @SJVanders

Contributors CV-P and GJ designed the study. LA, EBG, HR, SMS, SM and SV contributed to the media analysis. LM and SL-J contributed to the policy review. AD, $\mathrm{HF}, \mathrm{LMi}, \mathrm{NR}, \mathrm{KS}, \mathrm{GS}$, AS contributed to the telephone interviews. LA, SM, SV, ND, DJ, AD, LMi, NR, KS, GS, AS, LM, GJ, SMS and SL-J participated in the analysis of data. CV-P led the drafting of the manuscript, but all authors contributed to the writing and approved the final version before submission.

Funding The authors have not declared a specific grant for this research from any funding agency in the public, commercial or not-for-profit sectors.

Competing interests None declared.

Patient consent for publication Not required.

Ethics approval The study was reviewed and approved by the Health Research Authority (HRA) (IRAS: 282069) and the R\&D offices of the hospitals where the study took place.

Provenance and peer review Not commissioned; externally peer reviewed.

Data availability statement All data relevant to the study are included in the article or uploaded as online supplemental information.

This content has been supplied by the author(s). It has not been vetted by BMJ Publishing Group Limited (BMJ) and may not have been peer-reviewed. Any opinions or recommendations discussed are solely those of the author(s) and are not endorsed by BMJ. BMJ disclaims all liability and responsibility arising from any reliance placed on the content. Where the content includes any translated material, BMJ does not warrant the accuracy and reliability of the translations (including but not limited to local regulations, clinical guidelines, terminology, drug names and drug dosages), and is not responsible for any error and/or omissions arising from translation and adaptation or otherwise.

Open access This is an open access article distributed in accordance with the Creative Commons Attribution Non Commercial (CC BY-NC 4.0) license, which permits others to distribute, remix, adapt, build upon this work non-commercially, and license their derivative works on different terms, provided the original work is properly cited, appropriate credit is given, any changes made indicated, and the use is non-commercial. See: http://creativecommons.org/licenses/by-nc/4.0/.

\section{ORCID iD}

Cecilia Vindrola-Padros http://orcid.org/0000-0001-7859-1646

\section{REFERENCES}

1 Koh Y, Hegney DG, Drury V, et al. Comprehensive systematic review of healthcare workers' perceptions of risk and use of coping strategies towards emerging respiratory infectious diseases. Int $J$ Evid Based Healthc 2011;9:403-19.

2 Ives J, Greenfield S, Parry JM, et al. Healthcare workers' attitudes to working during pandemic influenza: a qualitative study. BMC Public Health 2009;9:56.

3 Imai $\mathrm{H}$, Matsuishi $\mathrm{K}$, Ito $\mathrm{A}$, et al. Factors associated with motivation and hesitation to work among health professionals during a public crisis: a cross sectional study of hospital workers in Japan during the pandemic (H1N1) 2009. BMC Public Health 2010;10:672.

4 Wu PE, Styra R, Gold WL. Mitigating the psychological effects of COVID-19 on health care workers. CMAJ 2020;192:E459-60.

5 Schwartz Jet al. Protecting Health Care Workers during the COVID-19 Coronavirus Outbreak -Lessons from Taiwan's SARS response. Clin Infect Dis 2020.

6 Raven J, Wurie H, Witter S, et al. Health workers' experiences of coping with the Ebola epidemic in Sierra Leone's health system: a qualitative study. BMC Health Serv Res 2018;18:251.

7 Bartoszko JJ, Farooqi MAM, Alhazzani W, et al. Medical masks vs N95 respirators for preventing COVID-19 in healthcare workers: a systematic review and meta-analysis of randomized trials. Influenza Other Respir Viruses 2020;14:365-73.

8 Chang D, Xu H, Rebaza A, et al. Protecting health-care workers from subclinical coronavirus infection. Lancet Respir Med 2020;8:e13.

9 The Lancet. COVID-19: protecting health-care workers. The Lancet 2020;395:922.

10 Sun N, Wei L, Shi S, et al. A qualitative study on the psychological experience of caregivers of COVID-19 patients. Am J Infect Control 2020;48:592-8.

11 Liu Q, Luo D, Haase JE, et al. The experiences of health-care providers during the COVID-19 crisis in China: a qualitative study. Lancet Glob Health 2020;8:e790-8.

12 Song X, Fu W, Liu X, et al. Mental health status of medical staff in emergency departments during the coronavirus disease 2019 epidemic in China. Brain Behav Immun 2020;88:60-5.

13 Ks F. The NHS at 70: how good is the NHS? 2018.

14 Willan J, King AJ, Jeffery K, et al. Challenges for NHS hospitals during covid-19 epidemic. BMJ 2020;368:m1117.

15 RCoA. View from the frontline of anaesthesia during COVID-19, 2020.

16 RCP. COVID-19 and its impact on the workforce, 2020.

17 Beebe J. Basic concepts and techniques of rapid appraisal. Hum Organ 1995;54:42-51.

18 Johnson GA, Vindrola-Padros C. Rapid qualitative research methods during complex health emergencies: a systematic review of the literature. Soc Sci Med 2017;189:63-75.

19 Tricco A, Langlois EV, Straus SE, et al. Rapid reviews to strengthen health policy and systems: a practical guide, 2017.

20 Gale NK, Heath G, Cameron E, et al. Using the framework method for the analysis of qualitative data in multi-disciplinary health research. BMC Med Res Methodol 2013;13:117-2288-13-117.

21 Khan Y, O'Sullivan T, Brown A, et al. Public health emergency preparedness: a framework to promote resilience. BMC Public Health 2018;18:1344.

22 Meltwater official website. Available: https://www.meltwater.com/en/ products/social-media-monitoring [Accessed 17 Sep 2020].

23 Vindrola-Padros C, Chisnall G, Cooper S, et al. Carrying out rapid qualitative research during a pandemic: emerging lessons from COVID-19. Qual Health Res 2020:104973232095152. 
24 DHSC. Coronavirus (COVID-19) scaling up our testing programmes, 2020.

25 PHE. Considerations for acute personal protective equipment (PPE) shortages, 2020.

26 NHS. NHS Muslim Network, and British Islamic Medical Association (BIMA). COVID-19 and Ramadan. How to support staff who may be fasting, 2020.

27 Legido-Quigley H, Mateos-García JT, Campos VR, et al. The resilience of the Spanish health system against the COVID-19 pandemic. Lancet Public Health 2020;5:e251-2.

28 Mackworth-Young C, Chingono R, Mavodza C, et al. Here, we cannot practice what is preached': early qualitative learning from community perspectives on Zimbabwe's response to COVID-19. Bull World Health Organ 2020.

29 Wong ELY, Samuel Yeung-shan W, Kin-fai HO, et al. Workplace safety and coronavirus disease(COVID-19) pandemic: survey of employees. Bull World Health Organ 2020.

30 Houghton C, Meskell P, Delaney H, et al. Barriers and facilitators to healthcare workers' adherence with infection prevention and control (IPC) guidelines for respiratory infectious diseases: a rapid qualitative evidence synthesis. Cochrane Database Syst Rev 2020;4:CD013582.
31 Coughlan C, Nafde C, Khodatars S, et al. COVID-19: lessons for junior doctors redeployed to critical care. Postgrad Med J 2020. [Epub ahead of print: 24 Jun 2020].

32 Marks S, Edwards S, Jerge EH. Rapid deployment of critical care nurse education during the COVID-19 pandemic. Nurse Lead 2020. doi:10.1016/j.mnl.2020.07.008. [Epub ahead of print: 25 Jul 2020].

33 England, NHS. Redeploying your secondary care medical workforce safely, 2020

34 Trainee Doctors Group - AoMRC. Plans regarding trainee redeployment during the COVID-19 pandemic - Position statement from the Academy Trainee Doctors' Group, 2020.

35 Vera San Juan N, Aceituno D, Djellouli N, et al. Healthcare Workers' mental health and wellbeing during the COVID-19 pandemic in the UK: contrasting guidelines with experiences in practice. medRxiv 2020.

36 Swaithes L, Dziedzic K, Sharp CA, et al. Context, context, context: how has covid-19 changed implementation globally and how can we 'lock in' learning? Rheumatology 2020;59:1804-7. 